Article

\title{
Effect of Polymer Demixed Nanotopographies on Bacterial Adhesion and Biofilm Formation
}

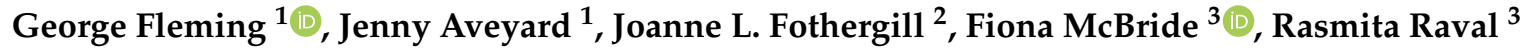 \\ and Raechelle A. D'Sa ${ }^{1, * \text { (D) }}$ \\ 1 School of Engineering, University of Liverpool, Liverpool L69 3GH, UK; sggflemi@liverpool.ac.uk (G.F.); \\ zippy78@liverpool.ac.uk (J.A.) \\ 2 Institute of Infection and Global Health, University of Liverpool, Liverpool L69 7B3, UK; \\ jofoth@liverpool.ac.uk \\ 3 The Open Innovation Hub for Antimicrobial Surfaces, Surface Science Research Centre, University of \\ Liverpool, Liverpool L69 3BX, UK; fmcbride@liverpool.ac.uk (F.M.); raval@liverpool.ac.uk (R.R.) \\ * Correspondence: r.dsa@liverpool.ac.uk
}

Received: 8 October 2019; Accepted: 19 November 2019; Published: 21 November 2019

\begin{abstract}
As the current global threat of antimicrobial resistance (AMR) persists, developing alternatives to antibiotics that are less susceptible to resistance is becoming an urgent necessity. Recent advances in biomaterials have allowed for the development and fabrication of materials with discrete surface nanotopographies that can deter bacteria from adhering to their surface. Using binary polymer blends of polystyrene (PS), poly(methyl methacrylate) (PMMA) and polycaprolactone (PCL) and varying their relative concentrations, PS/PCL, PS/PMMA and PCL/PMMA polymer demixed thin films were developed with nanoisland, nanoribbon and nanopit topographies. In the PS/PCL system, PS segregates to the air-polymer interface, with the lower solubility PCL preferring the substrate-polymer interface. In the PS/PMMA and PCL/PMMA systems, PMMA prefers the air-polymer interface due to its greater solubility and lower surface energy. The anti-adhesion efficacy of the demixed films were tested against Pseudomonas aeruginosa (PA14). PS/PCL and PCL/PMMA demixed films showed a significant reduction in cell counts adhered on their surfaces compared to pure polymer control films, while no reduction was observed in the counts adhered on PS/PMMA demixed films. While the specific morphology did not affect the adhesion, a relationship between bacterial cell and topographical surface feature size was apparent. If the surface feature was smaller than the cell, then an anti-adhesion effect was observed; if the surface feature was larger than the cell, then the bacteria preferred to adhere.
\end{abstract}

Keywords: antimicrobial; nanotopography; polymer demixing; biofilm; biointerfaces

\section{Introduction}

By 2050, it is predicted that the rise of resistant strains of bacteria and the ever-growing threat of antimicrobial resistance (AMR) will be the cause of 10 million deaths annually, and will burden the global economy by $£ 64$ trillion [1]. One of the leading factors for this surge of resistant superbugs is the misuse of current antibiotics in both clinical and agricultural settings [2-6]. Further problems arise when bacteria are able to irreversibly attach to a surface, which leads to microcolony formation and eventually biofilm maturation [7]. Indwelling medical devices, such as catheters, stents, dental implants, and orthopaedic prostheses, are susceptible to bacterial adhesion and frequently incur biofilm-associated infection [8-14]. Biofilm-associated bacteria are significantly more difficult to treat compared to their planktonic counterparts, with some estimates of their tolerance to antibiotics to be between $10^{2}$ and $10^{3}$ times higher [15-17]. As such, it is important that alternative solutions to combat biofilm-associated infections are developed. 
A promising alternative to current antibiotics and disinfectants in combatting biofilm infections is by physically altering the nanotopography to form surfaces unfavourable to bacterial adhesion. This strategy of developing anti-adhesive surfaces takes inspiration from nature: shark skin is made up of tooth-like micro-scales that promote low drag and do not allow fouling organisms to attach to the surface [18]. The nanotopography of the lotus leaf consists of small cone-like protuberances that result in a superhydrophobic surface. On these surfaces water droplets remain spherical and pick up bacteria and other contaminants, as they roll off [19]. Surface topoography can even be bactericidal as in the case of the cicada wing in which sharp nanopillars pierce the bacterial membrane [20].

Surface topography-based strategies are gaining popularity as alternatives to or to work in synergy with chemical strategies to impart an antibacterial effect. One particular methodology that has economic advantages compared to more expensive techniques, such as electron beam lithography, is polymer demixing. This technique uses the immiscibility of two polymers in a common solvent. Upon spin coating, the polymer blend spontaneously undergoes vertical then lateral phase separation to give thin polymer films with discrete nanotopographies. Recently, this technique was used to investigate the topographical effects of nanoislands on cellular response [21-26].

In this paper, we fabricate polymer demixed films with discrete nanotopographies from a range of binary blend systems using polystyrene (PS), polycaprolactone (PCL) and poly(methyl methacrylate) (PMMA) polymers. PS can be molded into a large number of materials due to it being a viscous liquid above its glass transition temperature. It has medium to high tensile strength, however it also has poor chemical, oxygen, UV resistance, and low impact strength, which can all be overcome by copolymerization. PCL is a biodegradable polymer that displays excellent low temperature flexibility and toughness. PMMA displays excellent light transmission, is tough, durable and lightweight and also has high resistance to UV and weathering. PCL has found uses in clinical applications such as orthopaedic coatings, sutures and drug delivery systems, while PMMA is used as materials for dental implants, bone cements, and intraocular lenses [27-31]. By using the polymer demixing process in this study, we were able to assess the nanotopographical effect on bacteria, while the underlying surface chemistry remained constant. Bacterial adhesion of Pseudomonas aeruginosa (PA14) was used in this study to develop a fundamental understanding of how topographical approaches using clinically relevant polymeric materials can pave the way to designing antibacterial (anti-adhesive) surfaces that will resist biofilm formation.

\section{Materials and Methods}

\subsection{Preparation of Polymer Demixed Thin Films}

Glass coverslips (13 $\mathrm{mm}$ in diameter) were cleaned by immersing them in $5 \% \mathrm{NaOH}$ for $30 \mathrm{~min}$, followed by concentrated $\mathrm{HNO}_{3}$ for $30 \mathrm{~min}$. Coverslips were then washed in $\mathrm{EtOH}(4 \times 2 \mathrm{~min})$, rinsed in DI water and dried at $80^{\circ} \mathrm{C}$. Coverslips were then treated with oxygen plasma for $1 \mathrm{~min}$. PS ( $\left.\mathrm{M}_{\mathrm{w}}: 280,000\right)$, PCL $\left(\mathrm{M}_{\mathrm{w}}: 48,000-90,000\right)$ and PMMA $\left(\mathrm{M}_{\mathrm{w}}: 350,000\right)$, all purchased from Sigma Aldrich, were dissolved in chloroform $\left(\mathrm{CHCl}_{3}\right)$ to give $5 \% \mathrm{w} / \mathrm{v}$ stock solutions. $1 \% \mathrm{w} / \mathrm{v}$ binary blend solutions of PS/PCL, PS/PMMA and PCL/PMMA were made by diluting and mixing the stock solutions in the following ratios: 0:100, 25:75, 50:50, 75:25 and 100:0. Aliquots of the blend solutions $(70 \mu \mathrm{L})$ were spin coated onto freshly cleaned coverslips at $4000 \mathrm{rpm}$ for $2 \mathrm{~min}$, using an SCS P6808P spin coater (Specialty Coating Systems Inc., Indianapolis, IN, USA). Spin coated films were dried in a vacuum desiccator at room temperature overnight, to allow evaporation of any remaining $\mathrm{CHCl}_{3}$.

\subsection{Contact Angle Analysis}

Static contact angles of water were used to determine changes in surface wettability following each step of the synthesis, using an Attension ThetaLite optical tensiometer (Biolin Scientific, Västra Frölunda, Sweden). The sessile drop method was used, and contact angles were taken at 17 frames per second for $10 \mathrm{~s}$ and data recorded using OneAttension software (Biolin Scientific, Västra Frölunda, 
Sweden). At least three readings were performed per sample type and the results recorded as the mean average \pm standard deviation.

\subsection{Fourier-Transform Infrared Spectroscopy Analysis}

Fourier-transform infrared (FTIR) spectra were obtained at room temperature in the spectral range between $3200 \mathrm{~cm}^{-1}$ and $1400 \mathrm{~cm}^{-1}$, using a PerkinElmer Frontier FTIR Spectrometer (Perkin Elmer, Llantrisant, UK). The spectra were obtained with 64 scans at resolution of $4 \mathrm{~cm}^{-1}$ and data was collected using PerkinElmer Spectrum v10.4 software (Perkin Elmer, Llantrisant, UK).

\subsection{X-ray Photoelectron Spectroscopy Analysis}

X-ray photoelectron spectroscopy (XPS) analysis was carried out on an Axis-Supra instrument (Kratos Analytical, Manchester, UK) using a monochromated $\mathrm{Al} \mathrm{K \alpha}$ X-ray source operating at a power of $225 \mathrm{~W}$. Charge compensation was performed using a low-energy electron flood source. Survey and narrow region scans were carried out at pass energies of 160 and $20 \mathrm{eV}$ and step sizes of 1 and $0.1 \mathrm{eV}$, respectively. Hybrid lens mode was used in both cases. Data were converted to vamas $\left({ }^{*}\right.$.vms) format and analysed using CasaXPS 2.3 software (Casa Software, Devon, UK). Spectra were calibrated to $285.0 \mathrm{eV}$, corrected with linear background removal and fitted using Gaussian-Lorentzian line curves.

\subsection{Atomic Force Microscopy Analysis}

Atomic force microscopy (AFM) was used to observe changes in surface topography occurring during synthesis. A Bruker Multimode 8 (Bruker, Billerica, MA, USA) system fitted with a NanoScope $\mathrm{V}$ controller was used, and samples were imaged in air in ScanAsyst mode using a silicon RTESPA-150A tip operating at a scan rate of $0.9 \mathrm{~Hz}$. Third order flattening was used to correct any errors while processing the image. $5 \times 5 \mu^{2}$ images were taken and root mean square roughness $(R q)$ and average roughness $(R a)$ were calculated from at least three replicates of each sample type, from at least three points per sample and measured using NanoScope Analysis 1.7 software (Bruker, Billerica, MA, USA). All data is presented in mean average \pm standard deviation.

\subsection{Adhered Cell Colony Forming Unit (CFU) Assay}

Antimicrobial tests were carried out against the P. aeruginosa laboratory reference strain, PA14, a highly virulent strain of Pseudomonas aeruginosa ( $P$. aeruginosa) with strong biofilm-forming capabilities [32] Overnight cultures of P. aeruginosa were diluted to McFarland Standard 0.5 in Luria-Bertani (LB) broth which is equal to approximately $1.5 \times 10^{8} \mathrm{CFU} / \mathrm{mL}$. Substrate disks were placed in 24-well plates and $2 \mathrm{~mL}$ of the bacterial solution added before incubating at $37^{\circ} \mathrm{C}$ for $24 \mathrm{~h}$ to allow biofilm formation. At the end of this time, substrate disks were transferred to sterile well plates and washed three time with Phosphate Buffer Saline (PBS) to remove any non-adhered planktonic bacteria. Substrates were then placed in fresh wells with fresh media and agitated vigorously, by pipette to remove and re-suspend the attached biofilm. A serial dilution was performed on LB agar using the Miles and Misra method in order to enumerate the bacteria from the biofilm [33]. All samples were studied in triplicate and repeated five times. The results were recorded as the mean average \pm standard error $\mathrm{CFU} / \mathrm{mL}$.

\subsection{Statistical Analysis}

The statistical analysis of bacterial numbers was performed using the data analysis package SigmaPlot 13.0 (Systat Software, San Jose, CA, USA). One-way analysis of variance (ANOVA) was used to establish differences between group means and thus variance between treatment types. Significance between treatment types was determined using the Student-Newman-Keuls (SNK) method. A value of $p<0.05$ was taken as statistically significant. 


\section{Results}

\subsection{Wettability: Contact Angle}

The wettability of the surfaces was determined using static contact angle analysis. The contact angles of polymer demixed films are recorded in Table 1. PS 100 exhibited the greatest hydrophobicity, with a contact angle of $83.8^{\circ}$. A lower contact angle was observed for PCL 100 and PMMA 100 with values of $76.2^{\circ}$ and $68.9^{\circ}$, respectively. For both PS/PCL and PS/PMMA demixed films an increase in contact angle was observed as the concentration of PS increased. As the concentration of PCL increased in the PCL/PMMA demixed films the contact angle too increased, showing an expected decrease in wettability.

Table 1. Static water contact angle measurements of polymer demixed films (PS/PCL, PS/PMMA, PCL/PMMA) with varying ratios (0:100, 25:75, 50:50, 75:25, 100:0). The results are presented as mean average \pm standard deviation. Matching superscript letters in each column indicate that there is a significant difference between the contact angles of these surfaces $(P<0.05)$.

\begin{tabular}{cccc}
\hline & PS:PCL & $\begin{array}{c}\text { Contact Angle } \\
\text { PS:PMMA }\end{array}$ & PCL:PMMA \\
\hline $0: 100$ & $76.2 \pm 1.2^{\mathrm{a}}$ & $68.9 \pm 1.6^{\mathrm{a}, \mathrm{f}}$ & $68.9 \pm 1.6^{\mathrm{a}}$ \\
$25: 75$ & $71.8^{\mathrm{b}} \pm 3.6^{\mathrm{b}}$ & $70.0 \pm 1.0^{\mathrm{b}, \mathrm{c}}$ & $67.2 \pm 2.4^{\mathrm{b}, \mathrm{c}}$ \\
$50: 50$ & $72.9 \pm 3.8^{\mathrm{c}, \mathrm{d}}$ & $68.6 \pm 2.4^{\mathrm{d}, \mathrm{e}}$ & $71.4 \pm 1.2^{\mathrm{b}}$ \\
$75: 25$ & $81.4 \pm 2.3^{\mathrm{b}, \mathrm{c}}$ & $81.1 \pm 5.3^{\mathrm{b}, \mathrm{d}, \mathrm{f}}$ & $72.7 \pm 2.8^{\mathrm{b}}$ \\
$100: 0$ & $83.8 \pm 1.5^{\mathrm{a}, \mathrm{b}, \mathrm{d}}$ & $83.8 \pm 1.5^{\mathrm{a}, \mathrm{c}, \mathrm{e}}$ & $76.2 \pm 1.2^{\mathrm{a}, \mathrm{c}}$ \\
\hline
\end{tabular}

\subsection{Surface Chemistry: FTIR}

The surface chemistry of the polymer demixed films was determined using FTIR and representative spectra are shown in Figure 1. The resulting spectrum of $\mathrm{PS}_{100}$ exhibited peaks at $3026 \mathrm{~cm}^{-1}$, due to the aromatic C-H stretching vibration $\left(v_{\text {aromatic }}\right)$ and at $2925 \mathrm{~cm}^{-1}$ due to the aliphatic stretch $\left(v_{\text {aliphatic }}\right)$. $\mathrm{PCL}_{100}$ was characterised with bands at $2948 \mathrm{~cm}^{-1}$ and $2865 \mathrm{~cm}^{-1}$ due to asymmetric $\left(v_{\mathrm{a}(\mathrm{CH})}\right)$ and symmetric $\mathrm{CH}_{2}$ stretching $\left(v_{\mathrm{s}(\mathrm{CH})}\right)$, respectively and at $1726 \mathrm{~cm}^{-1}$ due to carbonyl stretching $\left(v_{\mathrm{C}=\mathrm{O}}\right)$ [25]. Bands observed in the PMMA 100 spectrum at $2996 \mathrm{~cm}^{-1}, 2950 \mathrm{~cm}^{-1}$ and $1726 \mathrm{~cm}^{-1}$ were characteristic of $\mathrm{CH}_{3}$ stretching $\left(v_{\mathrm{CH} 3}\right), \mathrm{CH}_{2}$ stretching $\left(v_{\mathrm{CH} 2}\right)$ and carbonyl stretching $\left(v_{\mathrm{C}=\mathrm{O}}\right)$, respectively [25]. In PS/PCL films (Figure 1a), as the concentration of PS increased, the intensity of the carbonyl peak decreased and there was a subtle shift in the peak from $1726 \mathrm{~cm}^{-1}$ to $1730 \mathrm{~cm}^{-1}$. This relatively small shift in the carbonyl absorption band has also previously been observed by Mohamed et al. with blends of PCL and PS [34]. In PS/PMMA films (Figure 1b), as the relative concentration of PS increased, the emergence of a band at $3026 \mathrm{~cm}^{-1}$ was attributed the aromatic $\mathrm{C}-\mathrm{H}$ stretching of PS. In all spectra, except that of $\mathrm{PS}_{100}$, the carbonyl stretch specific to PMMA was observed. In PCL/PMMA films (Figure 1c) when the concentration of PCL increased the band was downshifted from $1732 \mathrm{~cm}^{-1}$ $\left(\mathrm{PCL}_{25} \mathrm{PMMA}_{75}\right)$ to $1728 \mathrm{~cm}^{-1}\left(\mathrm{PCL}_{75} \mathrm{PMMA}_{25}\right)$, as now the carbonyl band contribution is higher from PMMA in comparison with PCL [25]. 
(a)

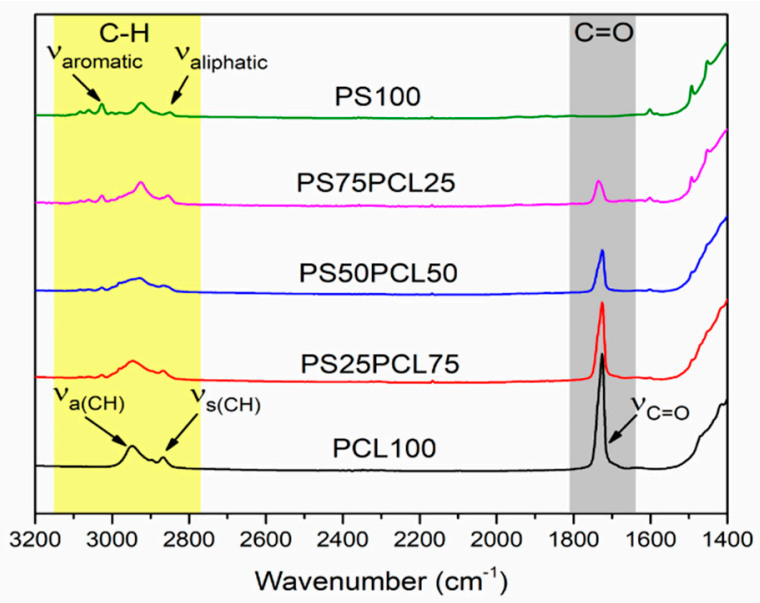

(b)

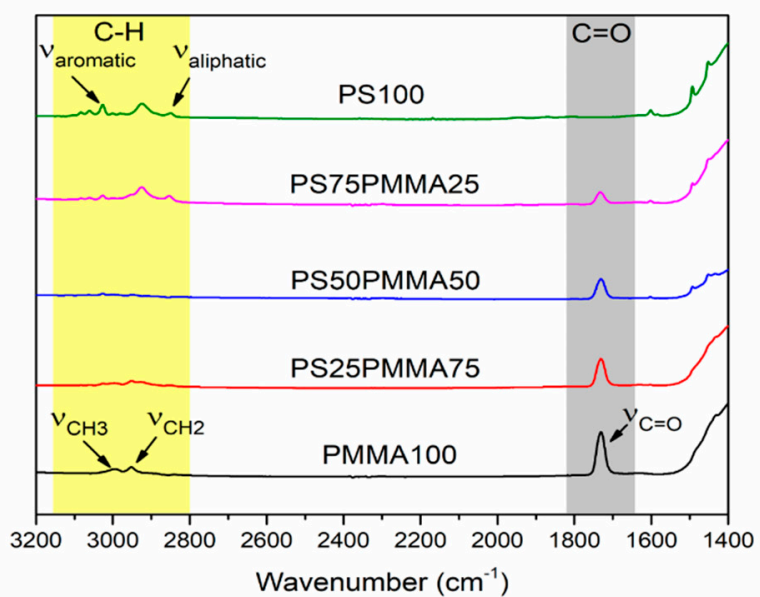

(c)

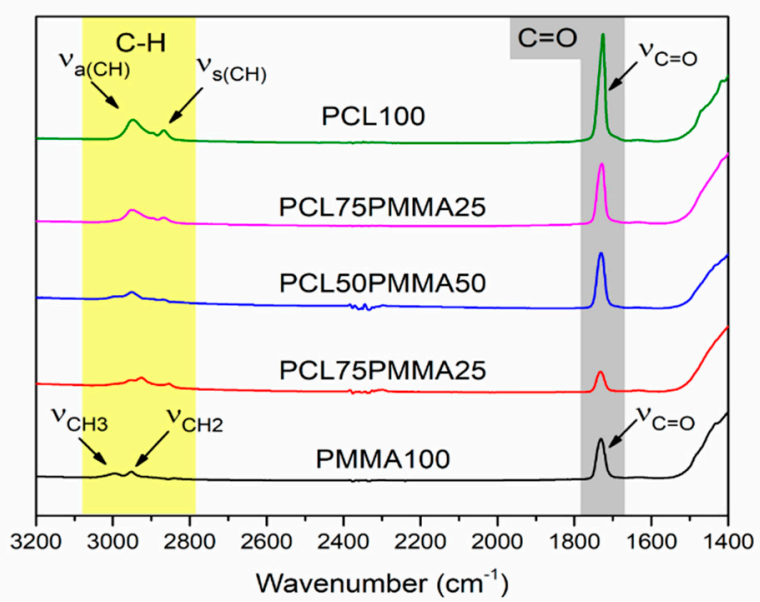

Figure 1. FTIR spectra of (a) PS/PCL (b) PS/PMMA and (c) PCL/PMMA demixed films.

\subsection{Surface Chemistry: XPS}

The elemental surface compositions of the polymer demixed films were determined by XPS analysis. The quantitative data is given in Table 2 and the spectra of the $C 1 \mathrm{~s}$ high resolution scans are shown in Figure 2. Curve fitting of the $\mathrm{C} 1$ s spectrum for $\mathrm{PS}_{100}$ gave three components: aromatic $\mathrm{C}-\mathrm{C} / \mathrm{C}-\mathrm{H}$ at $285.0 \mathrm{eV}$, aliphatic $\mathrm{C}-\mathrm{C} / \mathrm{C}-\mathrm{H}$ at $285.6 \mathrm{eV}$ and the $\pi-\pi^{*}$ shakeup at $291.7 \mathrm{eV}$. For both $\mathrm{PCL}_{100}$ and $\mathrm{PMMA}_{100}$, the $\mathrm{C} 1 \mathrm{~s}$ spectra was curve fitted into four components: $\mathrm{C}-\mathrm{C} / \mathrm{C}-\mathrm{H}$ at $285.0 \mathrm{eV}, \beta$-shifted 
$\mathrm{C}$ at $285.5 \mathrm{eV}, \mathrm{C}-\mathrm{O}$ at $286.3 \mathrm{eV}$ and $\mathrm{C}=\mathrm{O}$ at $289.1 \mathrm{eV}$. In PS / PCL films, the increase in relative PS concentration was indicated by the increase of at.\% contribution of the $\pi-\pi^{*}$ shakeup from $0.7 \%$ in $\mathrm{PS}_{25} \mathrm{PCL}_{75}$ up to $6.2 \%$ in $\mathrm{PS}_{100}$. The PCL-specific $\mathrm{C}-\mathrm{O}$ and $\mathrm{C}=\mathrm{O}$ component contributions decreased from $8.1 \%$ and $15.7 \%$ to $4.6 \%$ and $1.6 \%$, respectively, going from $\mathrm{PCL}_{100}$ to $\mathrm{PS}_{75} \mathrm{PCL}_{25}$. In PS/PMMA films, $\pi-\pi^{*}$ shakeup was not observed in $\mathrm{PS}_{25} \mathrm{PMMA}_{75}$ but contributed $1.2 \%$ of the $\mathrm{PS}_{50} \mathrm{PMMA}_{50}$ $\mathrm{C}$ 1s envelope and $2.0 \%$ of $\mathrm{PS}_{75} \mathrm{PMMA}_{25}$. The contribution of the PMMA-specific $\mathrm{C}-\mathrm{O}$ and $\mathrm{C}=\mathrm{O}$ components decreased from $18.3 \%(\mathrm{C}-\mathrm{O})$ and $15.2 \%(\mathrm{C}=\mathrm{O})$ in $\mathrm{PS}_{25} \mathrm{PMMA}_{75}$ to $9.1 \%(\mathrm{C}-\mathrm{O})$ and $6.5 \%$ $(\mathrm{C}=\mathrm{O})$ in $\mathrm{PS}_{75} \mathrm{PMMA}_{25}$. In PCL/PMMA films, there was no significant difference in at.\% contributions of $\beta$-shifted $\mathrm{C}, \mathrm{C}-\mathrm{O}$ and $\mathrm{C}=\mathrm{O}$ peaks in $\mathrm{PCL}_{25} \mathrm{PMMA}_{75}, \mathrm{PCL}_{50} \mathrm{PMMA}_{50}$ and $\mathrm{PCL}_{75} \mathrm{PMMA}_{25}$.

Table 2. XPS-derived at.\% of curve-fitted C 1s components for PS/PCL, PS/PMMA and PCL/PMMA demixed films.

\begin{tabular}{|c|c|c|c|c|c|}
\hline & \multicolumn{5}{|c|}{ C 1s Component at.\% (Binding Energy, eV) } \\
\hline & $\begin{array}{c}\text { C-C/C-H } \\
\text { Aliphatic } \\
\text { (285.0) }\end{array}$ & $\begin{array}{c}\beta \text {-shifted C } \\
\text { (C-C/C-H Aromatic) }^{a} \\
(285.5)\end{array}$ & $\begin{array}{c}\mathrm{C}-\mathrm{O} \\
(286.3)\end{array}$ & $\begin{array}{c}\mathrm{C}=\mathrm{O} \\
(289.1)\end{array}$ & $\begin{array}{c}\pi-\pi^{*} \\
(291.6)\end{array}$ \\
\hline PCL100 & $56.0 \pm 3.9$ & $15.9 \pm 0.7$ & $8.1 \pm 2.5$ & $15.7 \pm 0.6$ & - \\
\hline PS25PCL75 & $54.4 \pm 4.4$ & $21.7 \pm 4.7$ & $13.1 \pm 0.6$ & $10.2 \pm 0.3$ & $0.7 \pm 0.2$ \\
\hline PS50PCL50 & $69.3 \pm 7.5$ & $15.7 \pm 7.5$ & $8.4 \pm 0.5$ & $5.6 \pm 0.5$ & $1.3 \pm 0.4$ \\
\hline PS75PCL25 & $55.9 \pm 2.9$ & $34.0 \pm 2.9$ & $4.6 \pm 0.5$ & $1.6 \pm 0.7$ & $3.7 \pm 0.7$ \\
\hline PS100 & $69.7 \pm 0.6$ & $24.1 \pm 0.3^{\mathrm{a}}$ & - & - & $6.2 \pm 0.3$ \\
\hline PMMA100 & $38.0 \pm 1.3$ & $21.0 \pm 1.8$ & $21.4 \pm 2.0$ & $19.6 \pm 1.0$ & - \\
\hline PS25PMMA75 & $43.5 \pm 3.1$ & $23.0 \pm 4.2$ & $18.3 \pm 1.0$ & $15.2 \pm 1.0$ & - \\
\hline PS50PMMA50 & $54.7 \pm 4.5$ & $18.0 \pm 5.7$ & $15.1 \pm 1.5$ & $10.8 \pm 0.6$ & $1.2 \pm 0.1$ \\
\hline PS75PMMA25 & $62.2 \pm 3.7$ & $20.2 \pm 1.3$ & $9.1 \pm 3.5$ & $6.5 \pm 2.2$ & $2.0 \pm 0.6$ \\
\hline PS100 & $69.7 \pm 0.6$ & $24.1 \pm 0.3^{\mathrm{a}}$ & - & - & $6.2 \pm 0.3$ \\
\hline PMMA100 & $38.0 \pm 1.3$ & $21.0 \pm 1.8$ & $21.4 \pm 2.0$ & $19.6 \pm 1.0$ & - \\
\hline PCL25PMMA75 & $44.5 \pm 1.8$ & $18.3 \pm 0.6$ & $19.1 \pm 0.6$ & $18.4 \pm 0.2$ & - \\
\hline PCL50PMMA50 & $44.5 \pm 1.8$ & $17.7 \pm 0.8$ & $20.0 \pm 3.0$ & $17.8 \pm 0.4$ & - \\
\hline PCL75PMMA25 & $42.2 \pm 4.8$ & $21.4 \pm 4.2$ & $19.2 \pm 0.7$ & $17.3 \pm 0.2$ & - \\
\hline PCL100 & $56.0 \pm 3.9$ & $15.9 \pm 0.7$ & $8.1 \pm 2.5$ & $15.7 \pm 0.6$ & - \\
\hline
\end{tabular}

${ }^{a}$ The peak at $285.5 \mathrm{eV}$ for PS100 is due to C-C/C-H aromatic C 1 s components.

To analyse which polymer segregates to the air interface, the relative contribution of the ester $(\mathrm{C}=\mathrm{O})$ component to the $\mathrm{C}$ 1s envelope in the XPS spectra of the demixed films was compared to the $100 \%$ polymer control films, as previously reported by Ton-That and D'Sa [21,35]. In two of the systems studied (PS/PCL and PS/PMMA), the ester functional group is unique to one polymer (PCL and PMMA). As such, it is possible to determine the surface composition of each demixed PS/PCL and PS/PMMA films. In PCL/PMMA demixed films, the ester functional group is present in the backbone of each polymer and this method is unsuitable for this blend system. XPS analysis was carried out on polymer demixed films before and after curing at $80^{\circ} \mathrm{C}$ to determine whether the vertical phase separation was thermodynamically stable.

For both PS/PCL and PS/PMMA blend systems the arbitrary term ' $\mathrm{A}$ ' can be defined as the fraction of $\mathrm{O}-\mathrm{C}=\mathrm{O}$ peak in the $\mathrm{C} 1 \mathrm{~s}$ spectrum:

$$
\mathrm{A}=\left(\frac{I_{O-C=O}}{I_{C}}\right)
$$


(i) $\mathrm{PS} / \mathrm{PCL}$

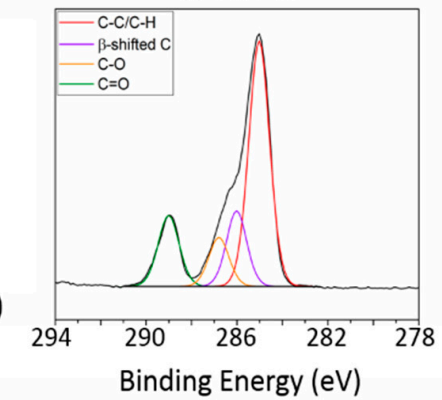

(b)

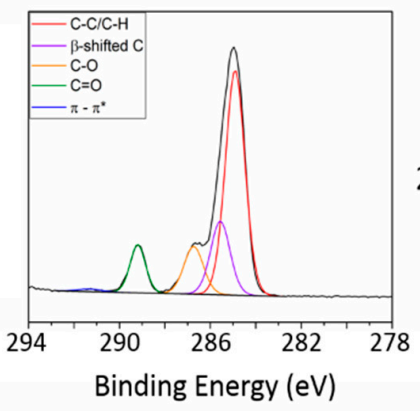

(c)

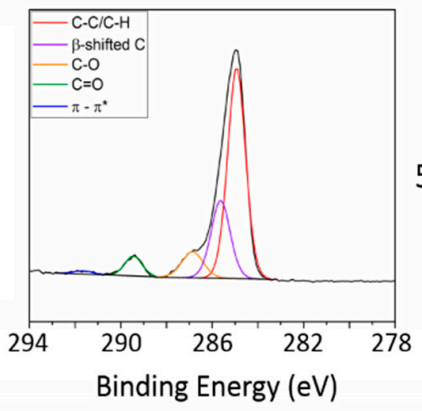

(d)

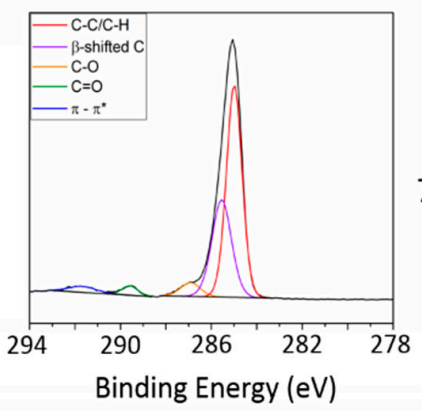

(e)

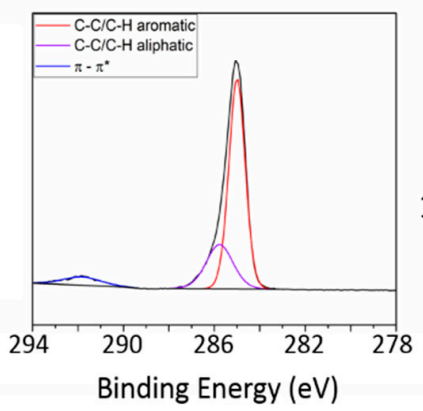

(ii) PS/PMMA
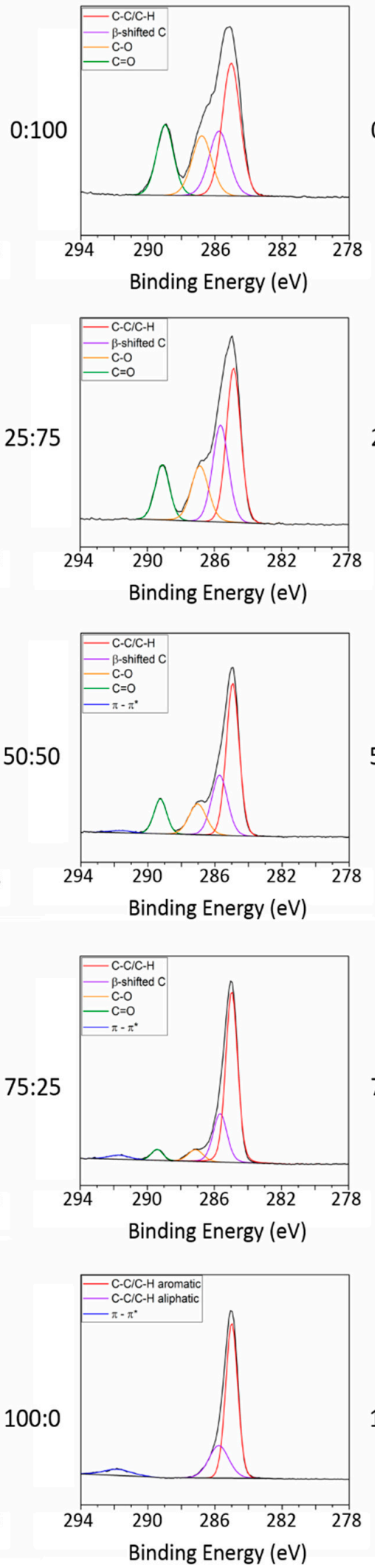

(iii) PCL/PMMA
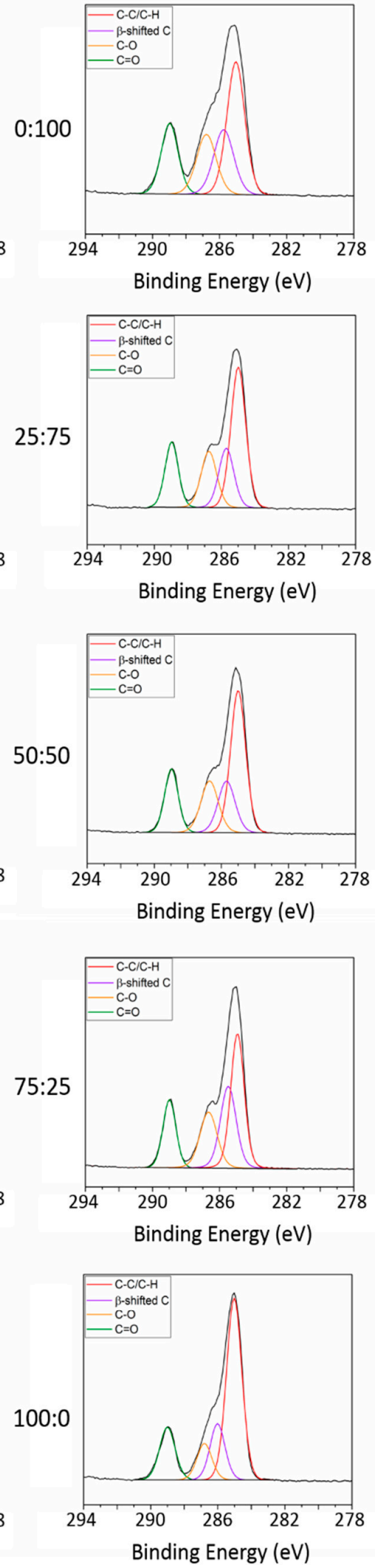

Figure 2. High resolution C 1s spectra of (i) PS/PCL, (ii) PS/PMMA and (iii) PCL/PMMA demixed films in varying ratios of (a) 0:100, (b) 25:75, (c) 50:50, (d) 75:25 and (e) 100:0. 
In PS/PCL blends the relative contribution of PCL is $6 X_{P C L}$ (six carbon atoms per repeat unit) and in PS/PMMA the relative contribution of PMMA is $5 X_{P M M A}$ (five carbon atoms per repeat unit). The relative contribution of PS in both blend systems is $8(1-X)$ (eight carbon atoms per repeat unit), where $X_{n}$ is the molar surface concentration of the polymer, to give:

$$
\mathrm{A}=\frac{X_{P C L}}{6 X_{P C L}+8\left(1-X_{P C L}\right)}
$$

for PS/PCL blends and,

$$
\mathrm{A}=\frac{X_{P M M A}}{5 X_{P M M A}+8\left(1-X_{P M M A}\right)}
$$

for PS/PMMA blends.

Rearranging (2) and (3) gives (4) and (5), respectively:

$$
\begin{gathered}
X_{P C L}=\frac{8 A}{2 A+1} \\
X_{P M M A}=\frac{8 A}{3 A+1}
\end{gathered}
$$

In Figures 3 and 4, the surface fraction of PCL and PMMA in PS/PCL and PS/PMMA demixed films, respectively, deduced from Equations (4) and (5), were compared to the equivalent composition of their corresponding $100 \%$ polymer film.

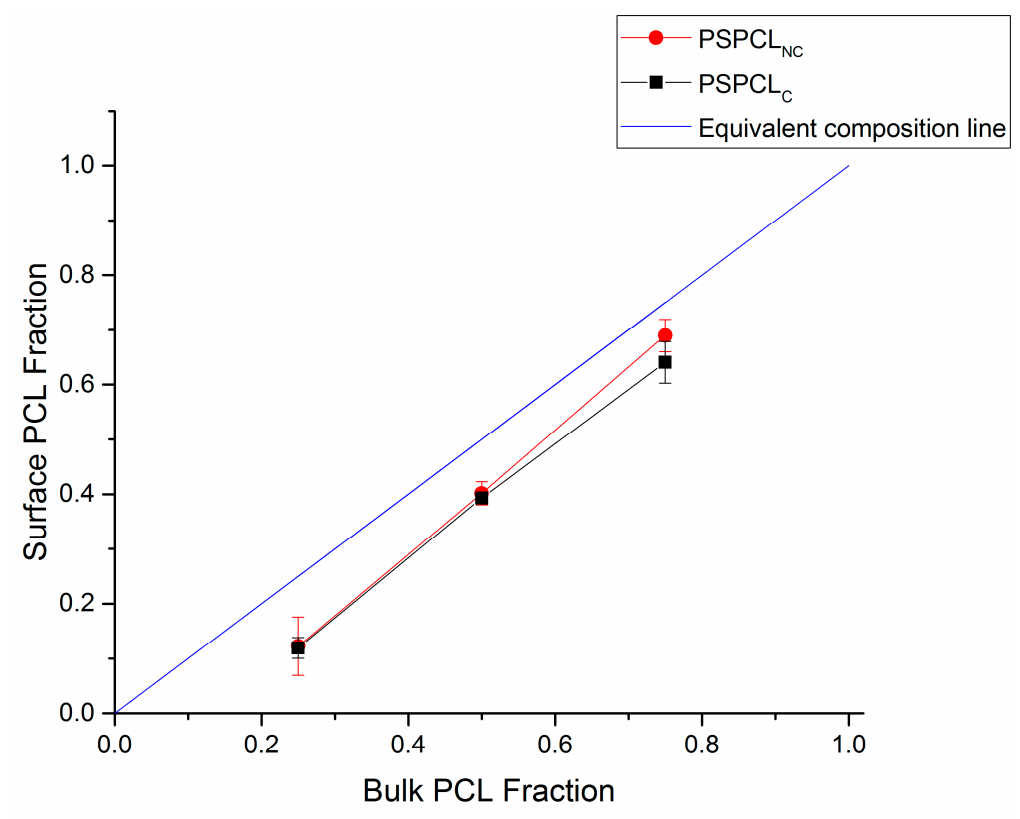

Figure 3. Plot of PS/PCL film surface PCL fraction vs. bulk PCL fraction. Data obtained using high resolution C 1s XPS measurements and Equation (4).

In PS/PCL demixed films, the surface fraction of PCL is below the theoretical equivalent composition line, indicating that PS segregates to the air interface, whereas in PS/PMMA demixed films the PMMA surface fraction is above the theoretical equivalent composition line, indicating that PMMA segregates to the air interface in this system. No movement of data points across the equivalent composition line indicates that the initial kinetic arrangement is also a thermodynamically stable one. 


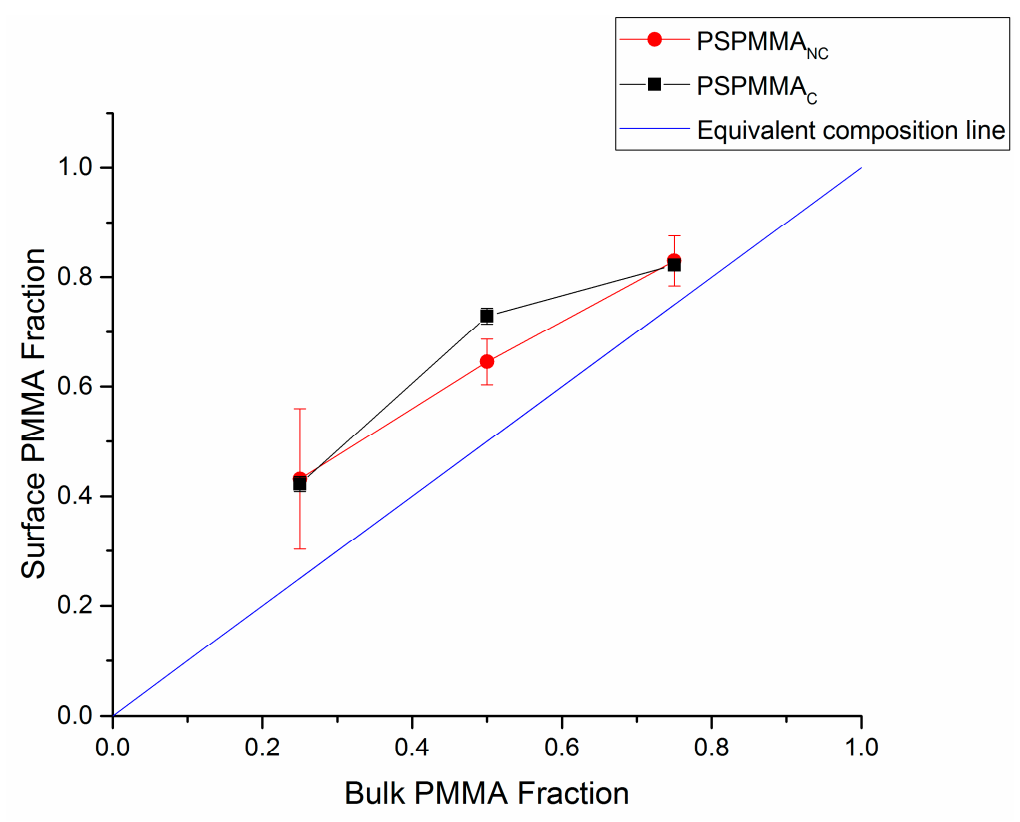

Figure 4. Plot of PS/PMMA film surface PMMA fraction vs. bulk PMMA fraction. Data obtained using high resolution C 1s XPS measurements and Equation (5).

\subsection{Surface Topography: AFM}

AFM was used to determine the surface topography of the polymer demixed films and representative height profiles are displayed in Figure 5. AFM derived data including surface features and roughness values $(R q, R a)$ are presented in Table 3 . The 100\% polymer control films exhibited flat surfaces with no features. The topography of the polymer demixed films was dependent on the blend system and the relative ratios of the polymers. In PS/PCL demixed films, when PCL was in excess an island topography was observed with average feature heights of $48 \mathrm{~nm}$ and average feature diameters of $185 \mathrm{~nm}$. $\mathrm{PS}_{50} \mathrm{PCL}_{50}$ demixed films formed ribbon topographies with average peak heights and diameters of $65 \mathrm{~nm}$ and $609 \mathrm{~nm}$, respectively. Pits were formed when PS was in abundance and the feature depths averaged $72 \mathrm{~nm}$ and the diameters $711 \mathrm{~nm}$. In PS/PMMA demixed films, when PMMA was the more concentrated polymer, islands were formed of average height $7 \mathrm{~nm}$ and average diameter $160 \mathrm{~nm}$. For both $\mathrm{PS}_{50} \mathrm{PMMA}_{50}$ and $\mathrm{PS}_{75} \mathrm{PMMA}_{25}$ demixed films a pit topography was displayed with average depths of 8 and $11 \mathrm{~nm}$ and diameters of 118 and $190 \mathrm{~nm}$, respectively. In PCL/PMMA demixed films, islands were formed for all polymer ratios. When PMMA was in abundance these islands were depressed in the apex, with average heights of $29 \mathrm{~nm}$ and average diameters of $232 \mathrm{~nm}$. When polymers were in equal concentration, islands were formed, $30 \mathrm{~nm}$ in height and $154 \mathrm{~nm}$ in diameter. The islands decreased in height (by an average of $16 \mathrm{~nm}$ ) when the PCL concentration increased to $75 \%$, but there was no significant difference between the diameter (on average $162 \mathrm{~nm}$ ) of the structures. 
(a)
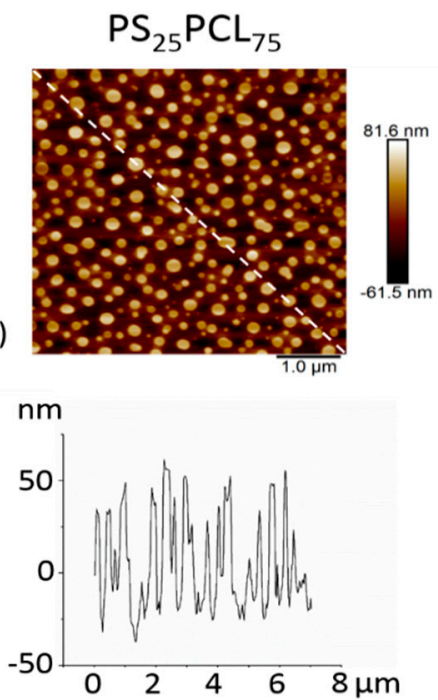

(d)
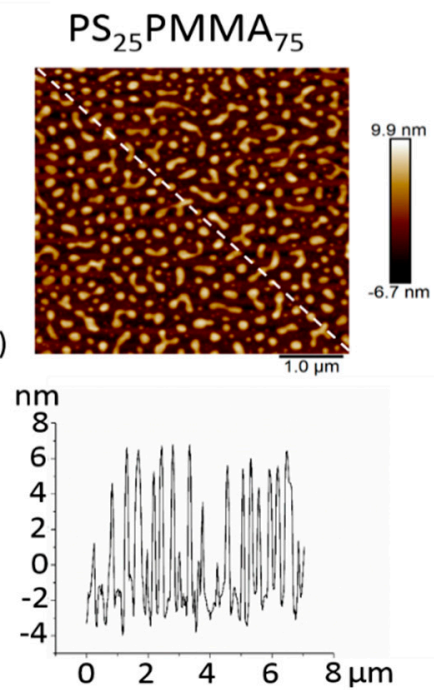

(g)
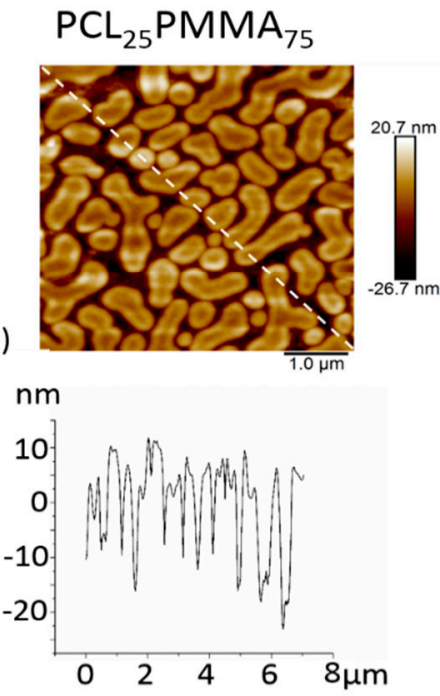

(b)
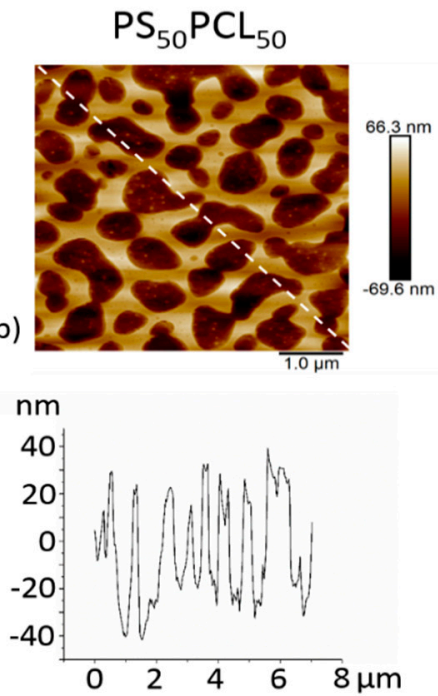

(e)

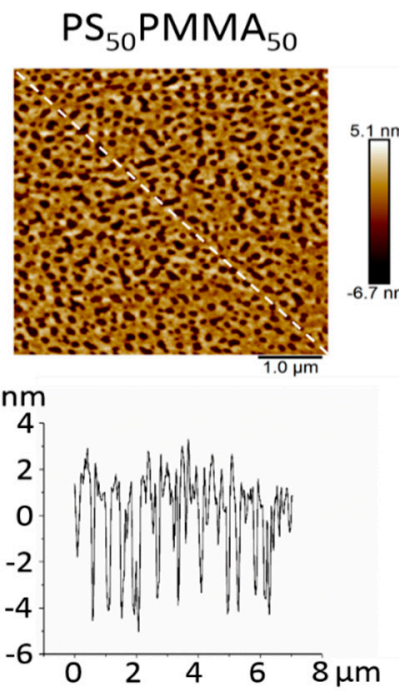

(h)
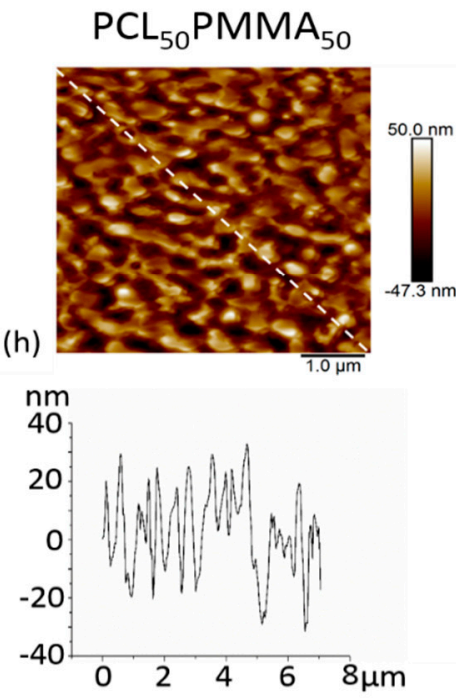

(c)
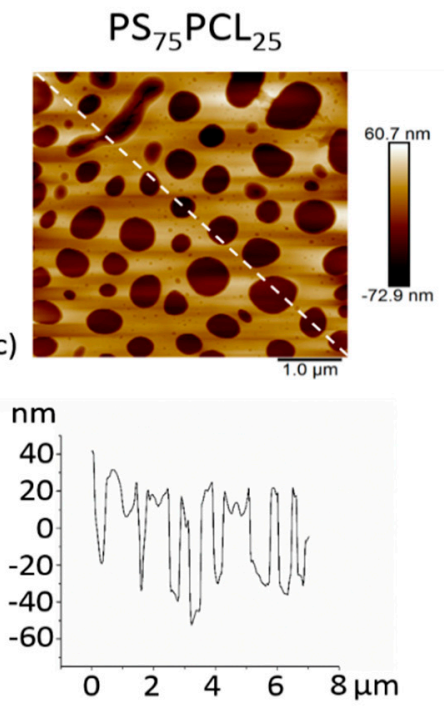

$$
\mathrm{PS}_{75} \mathrm{PMMA}_{25}
$$
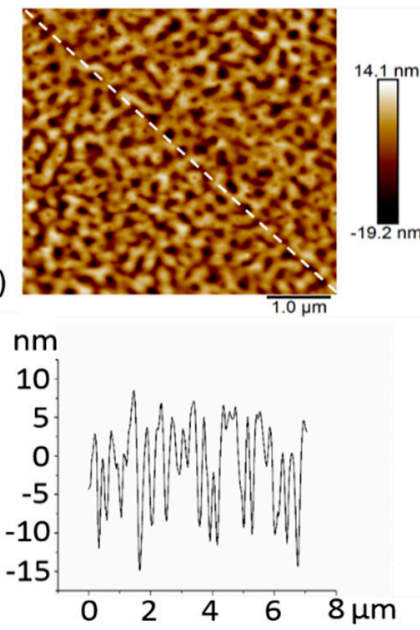

(i)
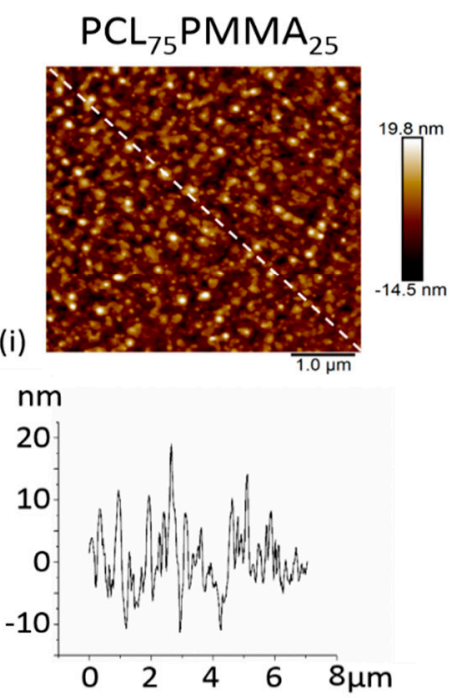

Figure 5. AFM 3D images and depth profiles of (a) $\mathrm{PS}_{25} \mathrm{PCL}_{75}$, (b) $\mathrm{PS}_{50} \mathrm{PCL}_{50}$, (c) $\mathrm{PS}_{75} \mathrm{PCL}_{25}$, (d) $\mathrm{PS}_{25} \mathrm{PMMA}_{75}$, (e) $\mathrm{PS}_{50} \mathrm{PMMA}_{50}$, (f) $\mathrm{PS}_{5} \mathrm{PMMA}_{25}$, (g) $\mathrm{PCL}_{25} \mathrm{PMMA}_{75}$, (h) $\mathrm{PCL}_{50} \mathrm{PMMA}_{50}$ and (i) $\mathrm{PCL}_{75} \mathrm{PMMA}_{25}$ demixed films. 
Table 3. Topographical data for PS/PCL, PS/PMMA, PCL/PMMA demixed films determined by AFM.

\begin{tabular}{|c|c|c|c|c|c|c|}
\hline & Topography & $\begin{array}{c}\text { Feature } \\
\text { Height/Depth (nm) }\end{array}$ & $\begin{array}{c}\text { Feature } \\
\text { Diameter (nm) }\end{array}$ & $\begin{array}{c}\text { Feature Spacing } \\
(\mathrm{nm})\end{array}$ & $R q(\mathrm{~nm})$ & $R a(\mathrm{~nm})$ \\
\hline $\mathrm{PCL}_{100}$ & flat & - & - & - & $5.2 \pm 1.4$ & $3.7 \pm 0.9$ \\
\hline $\mathrm{PS}_{25} \mathrm{PCL}_{75}$ & islands & $48 \pm 20$ & $185 \pm 53$ & $197 \pm 69$ & $17.3 \pm 5.5$ & $14.4 \pm 4.5$ \\
\hline $\mathrm{PS}_{50} \mathrm{PCL}_{50}$ & ribbons & $65 \pm 14$ & $609 \pm 185$ & $381 \pm 237$ & $21.3 \pm 4.3$ & $18.7 \pm 4.1$ \\
\hline $\mathrm{PS}_{75} \mathrm{PCL}_{25}$ & pits & $72 \pm 19$ & $711 \pm 239$ & $248 \pm 152$ & $23.9 \pm 4.4$ & $18.9 \pm 4.4$ \\
\hline $\mathrm{PS}_{100}$ & flat & - & - & - & $0.3 \pm 0.0$ & $0.2 \pm 0.0$ \\
\hline $\mathrm{PMMA}_{100}$ & flat & - & - & - & $0.3 \pm 0.1$ & $0.2 \pm 0.0$ \\
\hline $\mathrm{PS}_{25} \mathrm{PMMA}_{75}$ & islands & $7 \pm 2$ & $160 \pm 42$ & $200 \pm 69$ & $2.6 \pm 0.4$ & $2.2 \pm 0.4$ \\
\hline $\mathrm{PS}_{50} \mathrm{PMMA}_{50}$ & pits & $8 \pm 5$ & $118 \pm 39$ & $60 \pm 33$ & $3.2 \pm 1.2$ & $2.5 \pm 0.9$ \\
\hline $\mathrm{PS}_{75} \mathrm{PMMA}_{25}$ & pits & $11 \pm 4$ & $190 \pm 57$ & $88 \pm 28$ & $3.5 \pm 0.9$ & $2.7 \pm 0.7$ \\
\hline $\mathrm{PS}_{100}$ & flat & - & - & - & $0.3 \pm 0.0$ & $0.2 \pm 0.0$ \\
\hline PMMA $_{100}$ & flat & - & - & - & $0.3 \pm 0.1$ & $0.2 \pm 0.0$ \\
\hline $\mathrm{PCL}_{25} \mathrm{PMMA}_{75}$ & pitted islands & $29 \pm 12$ & $232 \pm 100$ & $145 \pm 101$ & $9.8 \pm 5.4$ & $8.4 \pm 5.0$ \\
\hline $\mathrm{PCL}_{50} \mathrm{PMMA}_{50}$ & islands & $30 \pm 20$ & $154 \pm 82$ & $191 \pm 113$ & $9.6 \pm 5.9$ & $7.9 \pm 4.7$ \\
\hline $\mathrm{PCL}_{75} \mathrm{PMMA}_{25}$ & islands & $16 \pm 5$ & $162 \pm 57$ & $186 \pm 92$ & $3.9 \pm 1.0$ & $2.9 \pm 0.8$ \\
\hline $\mathrm{PCL}_{100}$ & flat & - & - & - & $5.2 \pm 1.4$ & $3.7 \pm 0.9$ \\
\hline
\end{tabular}

\subsection{Bacterial Response: Adhered Cell CFU Assay}

Antibacterial activity was investigated against the lab strain of P. aeruginosa, PA14. An adhered cell CFU assay was performed, in which the surfaces were inoculated with bacteria for $24 \mathrm{~h}$ to allow any potential biofilm formation. After removal of any planktonic bacteria with a PBS wash, remaining viable bacteria from the surface were counted to test whether materials with structured surface topographies prevented adhesion and therefore biofilm formation. The cell counts for the adhered cell CFU assays are given in Figure 6 for PS/PCL, PS/PMMA and PCL/PMMA demixed films with 100\% polymer films as control surfaces. On PS/PCL demixed films (Figure 6a), all bacterial counts were significantly reduced compared to the control surfaces. The $\mathrm{PS}_{25} \mathrm{PCL}_{75}$ film reduced the bacterial count by $28 \%$ and $23 \%$ with respect to $\mathrm{PCL}_{100}$ and $\mathrm{PS}_{100}$. For $\mathrm{PS}_{50} \mathrm{PCL}_{50}$, reductions of $50 \%$ and $46 \%$ were observed for $\mathrm{PCL}_{100}$ and $\mathrm{PS}_{100}$, respectively. Finally, on the $\mathrm{PS}_{75} \mathrm{PCL}_{25}$ films the count was $49 \%$ less than $\mathrm{PCL}_{100}$ and $45 \%$ less than $\mathrm{PS}_{100}$. In PS/PMMA demixed films (Figure $6 \mathrm{~b}$ ), there was no statistically significant reduction for PA14 adhered cell CFU counts, compared to either $\mathrm{PS}_{100}$ or PMMA 100 . All PCL/PMMA demixed films (Figure 6c) exhibited statistically significant reductions in CFU counts compared to $\mathrm{PCL}_{100}$ and $\mathrm{PMMA}_{100}$. The counts on $\mathrm{PCL}_{25} \mathrm{PMMA}_{75}$ were reduced by $77 \%$ compared to on $\mathrm{PCL}_{100}$ and $72 \%$ compared to on $\mathrm{PMMA}_{100}$. For $\mathrm{PCL}_{50} \mathrm{PMMA}_{50}$, reductions of $78 \%$ and $73 \%$ were observed against $\mathrm{PCL}_{100}$ and $\mathrm{PMMA}_{100}$, respectively. The counts on $\mathrm{PCL}_{75} \mathrm{PMMA}_{25}$ were reduced by $76 \%$ and $70 \%$ compared to $\mathrm{PCL}_{100}$ and $\mathrm{PMMA}_{100}$, respectively.
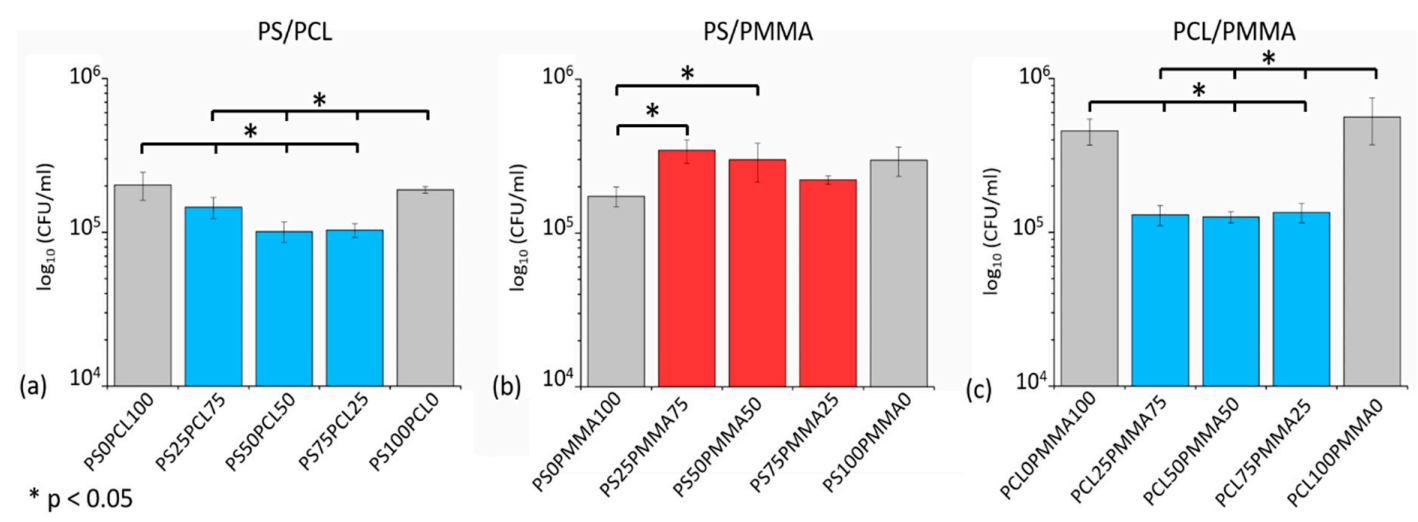

Figure 6. Viable adhered PA14 cell counts (CFU/mL) after 24 h growth on (a) PS/PCL, (b) PS/PMMA and (c) PCL/PMMA. The symbol '*' and blue bars indicate that all polymer demixed films have a statistically significant reduction in cell counts compared to controls $(p<0.05)$. Red bars indicate no statistically significant reduction or a statistically significant increase in cell count. Grey bars are pure polymer control surfaces. 


\section{Discussion}

Spin coating of demixed blends produces surfaces with discrete topographies and wettabilities. A schematic of the steps involved in polymer demixing is displayed in Figure 7 [36].

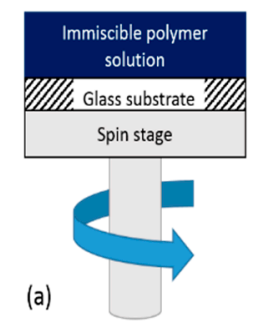

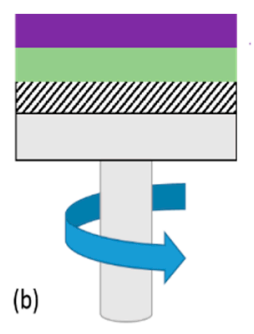

Vertical phase separation

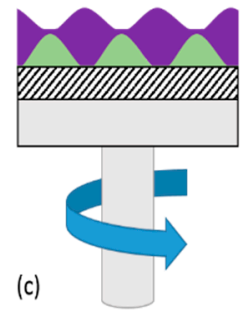

Interfacial instabilities

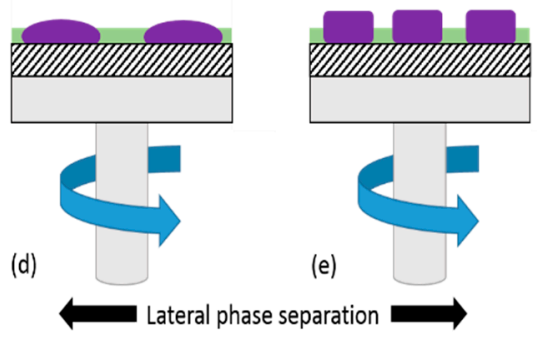

Figure 7. The polymer demixing process: a solution of two immiscible polymers is spun down and after an initial spin-off (a) the film splits vertically into two layers (b). Interfacial instabilities then occur between the polymer layers (c) leading to lateral phase separation (d), (e) [Adapted from Ref. 36].

The immiscibility of the two constituent polymers within a binary blend system when prepared in a common solvent is key to the phase separation phenomena that occur subsequently. Flory $[37,38]$ and Huggins [39] demonstrated that the entropic law that governs the immiscibility of low molecular weight (LMW) compounds $\left(\Delta G_{m}=\Delta H_{m}-T \Delta S_{m}\right)$ becomes an almost insignificant contributing factor for high molecular weight (HMW) materials, with an increase in molar mass leading to a decrease in $\Delta S_{m}$ resulting in $\Delta G_{m}>0$. Solvent and polymer are removed during the initial spin-off stage leading to formation of a bilayer in which one polymer segregates to the substrate interface and one to the air interface. The initial arrangement is purely kinetic with the least soluble polymer wetting the substrate followed by the more soluble polymer wetting the surface [35,40]. Thermodynamic factors may begin to play a role after time, and the polymer with the lowest surface free energy would be expected to segregate to the air interface to maintain the minimum interfacial energy [41,42], at the same time the higher molecular weight polymer tends to favour the substrate interface so as to avoid potential loss of conformational entropy associated with compression on the film surface [42,43].

In these experiments, the polymers were dissolved in chloroform. The Hildebrand solubility parameters for chloroform, PMMA, PS and PCL are 9.29, 8.80, 8.94 and 10.35, respectively. The closer the values of a polymer to that of its solvent generally indicates better solubility (PS $\approx \mathrm{PMMA}>\mathrm{PCL}$ in chloroform). In PS / PCL blends, the more soluble PS segregates to the surface even after curing at $80{ }^{\circ} \mathrm{C}$, despite having a higher surface energy (PS: $40.7 \mathrm{mN} / \mathrm{m}$, PCL: $30.8 \mathrm{mN} / \mathrm{m}$ ) [41,44,45] and despite the entropic penalty it incurs being the higher molecular weight component (PS: $280 \mathrm{kDa}, \mathrm{PCL}$ : $45 \mathrm{kDa}$ ). A possible explanation for this is that the pre-cleaning of the glass substrates renders the surface hydrophilic, thereby having a higher affinity for the more polar PCL [41].

While the solubility parameters of PS and PMMA are comparable, it can be assumed that PMMA has better solubility in chloroform from its segregation to the surface of the PS/PMMA films (Figure 4). Ton-That et al. investigated the effect of curing PS/PMMA demixed films after the spin coating process to allow the system to potentially reassemble under thermodynamic control [35]. Indeed, they observed 
that the initial orientation of the polymers was as a result of kinetics, with PMMA segregating to the air interface. Addition of heat to the system rearranged the polymer films, with PMMA migrating to the substrate interface owing to a higher surface energy.

In PS/PMMA demixed films the XPS analysis shows that PMMA prefers the air interface even after curing, despite having a comparable surface energy to PS (PS: $40.7 \mathrm{mN} / \mathrm{m}$, PMMA: $41.0 \mathrm{mN} / \mathrm{m}$ ) [44] and higher molecular weight (PS: $280 \mathrm{kDa}$, PMMA: $380 \mathrm{kDa}$ ). It is feasible that the curing conditions may have not been adequate to allow the blend system to reach thermodynamic equilibrium.

In the PCL/PMMA blends the ester component is present in both PCL and PMMA and so the XPS-derived relative ester method was unsuitable to determine surface composition for these blends. It can however, be hypothesised that due to higher solubility of PMMA in chloroform the PCL deposits first on the substrate, which is in agreement with the work carried out by Khattak et al. on PCL/PMMA blends [25]. PMMA has a greater surface energy (PCL: $30.8 \mathrm{mN} / \mathrm{m}$, PMMA: $41.0 \mathrm{mN} / \mathrm{m}$ ) [45,46] and higher molecular weight (PCL: $45 \mathrm{kDa}$, PMMA: $380 \mathrm{kDa}$ ) so it is hypothesised that the initial kinetic arrangement is most likely thermodynamically unstable and may result in a rearrangement of PCL to the surface.

The spin coating of polymer demixed blends in varying relative concentrations leads to the formation of films with island-, ribbon- and pit-like nanotopographical surface structures. This arises through complex dewetting pathways in which one or both polymer in the blend dewets the underlying surface, leading to lateral phase separation. The dewetting pathway depends on the relative concentrations of the polymers and the nature of the vertical phase separation. The dewetting of the two layers in the system is governed by the dynamics between the deformable polymer-air and polymer-polymer interfaces. An instability is induced between the two interfaces of the less concentrated (thinner) polymer layer [46]. Ma et al. reported on the underlying mechanisms involved in the formation of the surface morphologies seen in PS/PCL demixed films [41]. The report corroborates the findings in this work, observing that vertical separation occurs first with PS segregating to the air interface. They proposed that the thin upper PS layer results in instabilities at the interfaces of the layer, resulting in dewetting of the PS layer from the PCL layer to give PS islands as like for $\mathrm{PS}_{25} \mathrm{PCL}_{75}$. When the PS concentration increased vertical phase separation led to a liquid-liquid dewetting process, in which both films dewet their underlying surface. The PS chains lose mobility as the solvent evaporates and this results in ribbon-like structures as seen on $\mathrm{PS}_{50} \mathrm{PCL}_{50}$ surfaces. When the concentration of PS increased, further dewetting led to the growth of holes, like the pits observed for $\mathrm{PS}_{75} \mathrm{PCL}_{25}$ blends.

De Silva et al. demonstrated that by varying the concentrations of the polymers in PS/PMMA blends and as a result, the relative thicknesses of the individual polymer layers, the instability can be transferred between layers [47]. It was seen that when the PMMA top layer was thinner than the underlying PS layer the instability was between the interfaces of the PMMA layers. Vice versa, when the PMMA concentration increased (thicker layer) on top of the thinner PS layer a transition to an unstable PS layer was observed. It is, therefore, most likely that the island-rich topography observed on the surface of $\mathrm{PS}_{25} \mathrm{PMMA}_{75}$ films is due to an initial dewetting of PS from the surface, and the pits formed on $\mathrm{PS}_{75} \mathrm{PMMA}_{25}$ most likely due to the growth of holes, initiated by the dewetting of PMMA on the PS layer. The hypothesis that the more soluble PMMA segregates to the air interface corroborates Khattak's work on PCL/PMMA [25]. From the reports by both Ma and de Silva, it can be concluded that the initial interfacial instability occurs in the lower concentration (thinner) layer [41,47]. In $\mathrm{PCL}_{25} \mathrm{PMMA}_{75}$ the pitted island formation is likely formed through an initial instability in the underlying PCL layer dewetting the substrate, while the island morphology seen for PCL $75 \mathrm{PMMA}_{25}$ begins with an instability in the PMMA layer, dewetting the PCL layer.

In this study, the polymer demixed films were assayed for their anti-adhesion efficacy against $P$. aeruginosa (PA14), using an adhered cell CFU assay to see if biofilm formation could be prevented. An inoculating period of $24 \mathrm{~h}$ was chosen to allow the potential for irreversible adhesion and subsequent biofilm formation to occur. A study by Lu et al. in 2016, reported the anti-adhesive properties of polydimethylsiloxane (PDMS) with micropatterned surfaces [48]. A significant reduction in bacterial 
adhesion was observed for three different species of bacteria (E. coli, S. aureus, and P. aeruginosa). When the pattern size was smaller than the bacterial cell diameter an improved anti-adhesion effect was observed; when the pattern size was comparable or larger than the bacterial cell, the anti-adhesion effect was reduced.

Of the three polymer blend systems used in this study, PS/PCL and PCL/PMMA demixed films showed a significant reduction in bacterial adhesion compared to their corresponding $100 \%$ polymer control films. For PS/PCL demixed films $\mathrm{PS}_{50} \mathrm{PCL}_{50}$ and $\mathrm{PS}_{75} \mathrm{PCL}_{25}$ showed increased antibacterial activity compared to $\mathrm{PS}_{25} \mathrm{PCL}_{75}$, whereas there was no statistical significance between cell counts on the surface of the PCL/PMMA demixed films. This is probably due to the fact that topographies exhibited by PCL/PMMA films did not vary in shape and size as drastically as in PS/PCL films. The results corroborate Lu's [48] findings with the diameters of the nanotopographical surface features of the demixed films being smaller than the experimental diameter of PA14 cells $(1.7 \pm 0.3 \mu \mathrm{m})$ (Supporting information, Figure S2). No reduction in bacterial adhesion was observed for PS/PMMA demixed films when compared to their corresponding $100 \%$ polymer control films. After $24 \mathrm{~h}$ soaking in LB broth, the diameters of the nanotopographical surface features of all PS/PMMA demixed films (Supporting information, Table S1, Figure S1) had increased to sizes comparable to the bacterial cell diameter. This was also in agreement with Lu's observations [49] that the anti-adhesion effect is reduced when cell and structure diameters are comparable.

Hochbaum and Aizenberg demonstrated the ability to the affect the spontaneous ordering and arrangement of $P$. aeruginosa cells on nanostructured substrate surfaces by altering the spacing between structures [49]. The bacteria were seen to arrange themselves so as to maximise the cell-surface contact area. When the spacing was larger than the cell diameter, the adhesion of the bacteria on the surface was random; when the spacing between features was comparable to the diameter of the cell, the bacteria positioned themselves parallel to the substrate and perpendicular to one another, in contact with multiple surface structures; when the structures were smaller than the diameter of the cell, the bacteria were no longer able to arrange themselves parallel to the surface and oriented so as to adhere to the vertical length of the structures, perpendicular to the surface. In this study, the spacing between features on the surface of the anti-adhesive PS/PCL and PCL/PMMA demixed films were significantly smaller than the length of the cell. The heights of these surface structures were also shorter than the length of the cell meaning that a vertical arrangement perpendicular to the surface would not benefit the bacteria in maximising cell-surface contact area. As such these two polymer blend systems (PS/PCL, PCL/PMMA) were able to produce topographies that were anti-adhesive to the bacteria by preventing the bacteria from maximising their cell-surface contact area. Future studies within the group are looking using at using different fabrication technologies for generating specific features with well-defined spacings, pitches and heights further understand bacterial adhesion to nanotopographies.

\section{Conclusions}

In summary, we used a cost-effective, polymer demixing protocol to produce binary polymer demixed thin films with varying topographies and wettabilities. The nanotopographical structures varied between islands, ribbons and pits, depending on the polymer blend system used and the relative concentrations of the two polymers, within the blends. The anti-adhesive activity and thus prevention of biofilm formation of the polymer demixed films was assessed against P. aeruginosa (PA14) after $24 \mathrm{~h}$. All PS/PCL and PCL/PMMA demixed films showed anti-adhesive properties when compared to their corresponding $100 \%$ polymer control films; PS/PMMA demixed films showed no anti-adhesive ability. The link between feature size/spacing distance and cell diameter is in agreement with the conclusions drawn from the literature $[48,49]$. PS/PCL and PCL/PMMA demixed films were prepared with feature size and spacing between features much smaller than the bacterial cell. As a result, of this the surface was less desirable for the bacteria to adhere to due to the inability to maximise cell-surface contact area.

Supplementary Materials: The following are available online at http://www.mdpi.com/2073-4360/11/12/1921/s1, Table S1. Topographical data for PS/PCL, PS/PMMA, PCL/PMMA demixed films soaked in LB broth for 
$24 \mathrm{~h}$, determined by AFM. Figure S1. AFM 3D images and depth profiles of (a) $\mathrm{PS}_{25} \mathrm{PCL}_{75}$, (b) $\mathrm{PS}_{50} \mathrm{PCL}_{50}$, (c) $\mathrm{PS}_{75} \mathrm{PCL}_{25}$, (d) $\mathrm{PS}_{25} \mathrm{PMMA}_{75}$, (e) $\mathrm{PS}_{50} \mathrm{PMMA}_{50}$, (f) PS75PMMA 25 , (g) $\mathrm{PCL}_{25} \mathrm{PMMA}_{75}$, (h) PCL ${ }_{50} \mathrm{PMMA}_{50}$ and (i) PCL $75 \mathrm{PMMA}_{25}$ demixed films, after soaking in LB broth for $24 \mathrm{~h}$. Figure S2. Representative SEM images of PA14 fixed onto glass slides after $24 \mathrm{~h}$ incubation time. (Average cell diameter $1.7 \pm 0.3 \mu \mathrm{m}$ ).

Author Contributions: G.F. performed majority of the experiments and contributed to writing of the paper; J.A. conceived and designed the experiments and contributed to the interpretation of the results; J.L.F. contributed to the microbiology experiments and interpretation; F.M. and R.R. contributed to the XPS analysis; R.A.D. contributed to the interpretation and discussion of the results and writing of the paper.

Acknowledgments: Authors gratefully acknowledge the funding for this project which was provided by an Engineering and Physical Sciences Research Council (EPSRC) First Grant (EP/MO27325/1) and an EPSRC DTA studentship.

Conflicts of Interest: The authors declare no conflict of interest.

\section{References}

1. O'Neill, J. Tackling Drug-Resistant Infections Globally: Final Report and Recommendations-The Review on Antimicrobial Resistance Chaired by Jim O'Neill; Wellcome Trust and HM Government: London, UK, 2016.

2. Angulo, F.J.; Baker, N.L.; Olsen, S.J.; Anderson, A.; Barrett, T.J. Antimicrobial use in agriculture: Controlling the transfer of antimicrobial resistance to humans. Semin. Pediatr. Infect. Dis. 2004, 15, 78-85. [CrossRef]

3. Thanner, S.; Drissner, D.; Walsh, F. Antimicrobial resistance in agriculture. mBio 2016, 7. [CrossRef]

4. Witte, W. Medical consequences of antibiotic use in agriculture. Am. Assoc. Adv. Sci. 1998, 279, $996-997$.

5. McGowan, J.E., Jr. Antimicrobial resistance in hospital organisms and its relation to antibiotic use. Rev. Infect. Dis. 1983, 5, 1033-1048. [CrossRef]

6. Ventola, C.L. The antibiotic resistance crisis: Part 1: Causes and threats. Pharm. Ther. 2015, 40, 277.

7. Stoodley, P.; Sauer, K.; Davies, D.G.; Costerton, J.W. Biofilms as complex differentiated communities. Ann. Rev. Microbiol. 2002, 56, 187-209. [CrossRef]

8. Maki, D.G.; Stolz, S.M.; Wheeler, S.; Mermel, L.A. Prevention of central venous catheter-related bloodstream infection by use of an antiseptic-impregnated catheter: A randomized, controlled trial. Ann. Intern. Med. 1997, 127, 257-266. [CrossRef]

9. Elliott, T.; Moss, H.; Tebbs, S.; Wilson, I.; Bonser, R.; Graham, T.; Burke, L.; Faroqui, M. Novel approach to investigate a source of microbial contamination of central venous catheters. Eur. J. Clin. Microbiol. Infect. Dis. 1997, 16, 210-213. [CrossRef]

10. Stickler, D. Bacterial biofilms and the encrustation of urethral catheters. Biofouling 1996, 9, 293-305. [CrossRef]

11. Reid, G.; Denstedt, J.D.; Kang, Y.S.; Lam, D.; Nause, C. Microbial adhesion and biofilm formation on ureteral stents in vitro and in vivo. J. Urol. 1992, 148, 1592-1594. [CrossRef]

12. Busscher, H.; Rinastiti, M.; Siswomihardjo, W.; Van der Mei, H. Biofilm formation on dental restorative and implant materials. J. Dent. Res. 2010, 89, 657-665. [CrossRef]

13. Garvin, K.L.; Hanssen, A.D. Infection after total hip arthroplasty. Past, present, and future. JBJS 1995, 77, 1576-1588. [CrossRef]

14. Sanderson, P. Infection in orthopaedic implants. J. Hosp. Infect. 1991, 18, 367-375. [CrossRef]

15. Anwar, H.; Costerton, J. Enhanced activity of combination of tobramycin and piperacillin for eradication of sessile biofilm cells of Pseudomonas aeruginosa. Antimicrob. Agents Chemother. 1990, 34, 1666-1671. [CrossRef]

16. Høiby, N.; Bjarnsholt, T.; Givskov, M.; Molin, S.; Ciofu, O. Antibiotic resistance of bacterial biofilms. Int. J. Antimicrob. Agents 2010, 35, 322-332. [CrossRef]

17. Moskowitz, S.M.; Foster, J.M.; Emerson, J.; Burns, J.L. Clinically feasible biofilm susceptibility assay for isolates of Pseudomonas aeruginosa from patients with cystic fibrosis. J. Clin. Microbiol. 2004, 42, 1915-1922. [CrossRef]

18. Bixler, G.D.; Bhushan, B. Fluid Drag Reduction with Shark-Skin Riblet Inspired Microstructured Surfaces. Adv. Funct. Mater. 2013, 23, 4507-4528. [CrossRef]

19. Barthlott, W.; Neinhuis, C. Purity of the sacred lotus, or escape from contamination in biological surfaces. Planta 1997, 202, 1-8. [CrossRef] 
20. Ivanova, E.P.; Hasan, J.; Webb, H.K.; Truong, V.K.; Watson, G.S.; Watson, J.A.; Baulin, V.A.; Pogodin, S.; Wang, J.Y.; Tobin, M.J. Natural bactericidal surfaces: Mechanical rupture of Pseudomonas aeruginosa cells by cicada wings. Small 2012, 8, 2489-2494. [CrossRef]

21. D'Sa, R.A.; Raj, J.; Dickinson, P.J.; McCabe, F.; Meenan, B.J. Human fetal osteoblast response on poly (methyl methacrylate)/polystyrene demixed thin film blends: Surface chemistry vs topography effects. ACS Appl. Mater. Interfaces 2015, 8, 14920-14931. [CrossRef]

22. Dalby, M.; Giannaras, D.; Riehle, M.; Gadegaard, N.; Affrossman, S.; Curtis, A. Rapid fibroblast adhesion to $27 \mathrm{~nm}$ high polymer demixed nano-topography. Biomaterials 2004, 25, 77-83. [CrossRef]

23. Dalby, M.J. Cellular response to low adhesion nanotopographies. Int. J. Nanomed. 2007, 2, 373.

24. Dalby, M.J.; Yarwood, S.J.; Riehle, M.O.; Johnstone, H.J.; Affrossman, S.; Curtis, A.S. Increasing fibroblast response to materials using nanotopography: Morphological and genetic measurements of cell response to 13-nm-high polymer demixed islands. Exp. Cell Res. 2002, 276, 1-9. [CrossRef]

25. Khattak, M.; Pu, F.; Curran, J.M.; Hunt, J.A.; D'Sa, R.A. Human mesenchymal stem cell response to poly (E-caprolactone/poly (methyl methacrylate) demixed thin films. J. Mater. Sci. Mater. Med. 2015, $26,178$. [CrossRef]

26. Lim, J.Y.; Hansen, J.C.; Siedlecki, C.A.; Runt, J.; Donahue, H.J. Human foetal osteoblastic cell response to polymer-demixed nanotopographic interfaces. J. R. Soc. Interface 2005, 2, 97-108. [CrossRef]

27. Coombes, A.; Rizzi, S.; Williamson, M.; Barralet, J.; Downes, S.; Wallace, W. Precipitation casting of polycaprolactone for applications in tissue engineering and drug delivery. Biomaterials 2004, 25, 315-325. [CrossRef]

28. Kim, S.B.; Kim, Y.J.; Yoon, T.L.; Park, S.A.; Cho, I.H.; Kim, E.J.; Kim, I.A.; Shin, J.-W. The characteristics of a hydroxyapatite-chitosan-PMMA bone cement. Biomaterials 2004, 25, 5715-5723. [CrossRef]

29. Klawitter, J.J.; Weinstein, A.M.; Peterson, L.J. Fabrication and characterization of porous-rooted polymethylmethacrylate (PMMA) dental implants. J. Dent. Res. 1977, 56, 385-393. [CrossRef]

30. Pillai, C.K.S.; Sharma, C.P. Absorbable polymeric surgical sutures: Chemistry, production, properties, biodegradability, and performance. J. Biomater. Appl. 2010, 25, 291-366. [CrossRef]

31. Terrada, C.; Julian, K.; Cassoux, N.; Prieur, A.-M.; Debre, M.; Quartier, P.; LeHoang, P.; Bodaghi, B. Cataract surgery with primary intraocular lens implantation in children with uveitis: Long-term outcomes. J. Cataract Refract. Surg. 2011, 37, 1977-1983. [CrossRef]

32. Lee, D.G.; Urbach, J.M.; Wu, G.; Liberati, N.T.; Feinbaum, R.L.; Miyata, S.; Diggins, L.T.; He, J.; Saucier, M.; Déziel, E. Genomic analysis reveals that Pseudomonas aeruginosa virulence is combinatorial. Genome Biol. 2006, 7, 90. [CrossRef]

33. Miles, A.A.; Misra, S.; Irwin, J. The estimation of the bactericidal power of the blood. Epidemiol. Infect. 1938, 38, 732-749. [CrossRef]

34. Mohamed, A.; Gordon, S.H.; Biresaw, G. Polycaprolactone/polystyrene bioblends characterized by thermogravimetry, modulated differential scanning calorimetry and infrared photoacoustic spectroscopy. Polym. Degrad Stabil 2007, 92, 1177-1185. [CrossRef]

35. Ton-That, C.; Shard, A.; Daley, R.; Bradley, R. Effects of annealing on the surface composition and morphology of PS/PMMA blend. Macromolecules 2000, 33, 8453-8459. [CrossRef]

36. Heriot, S.Y.; Jones, R.A.L. An interfacial instability in a transient wetting layer leads to lateral phase separation in thin spin-cast polymer-blend films. Nat. Mater. 2005, 4, 782-786. [CrossRef]

37. Flory, P.J. Principles of Polymer Chemistry Ithaca; Cornell University: New York, NY, USA, 1953.

38. Flory, P.J. Thermodynamics of high polymer solutions. J. Chem. Phys. 1942, 10, 51-61. [CrossRef]

39. Huggins, M.L. Solutions of long chain compounds. J. Chem. Phys. 1941, 9, 440. [CrossRef]

40. Ton-That, C.; Shard, A.G.; Teare, D.O.H.; Bradley, R.H. XPS and AFM surface studies of solvent-cast PS/PMMA blends. Polymer 2001, 42, 1121-1129. [CrossRef]

41. Ma, M.; He, Z.; Yang, J.; Wang, Q.; Chen, F.; Wang, K.; Zhang, Q.; Deng, H.; Fu, Q. Vertical Phase Separation and Liquid-Liquid Dewetting of Thin PS/PCL Blend Films during Spin Coating. Langmuir 2011, 27, 1056-1063. [CrossRef]

42. Tanaka, K.; Takahara, A.; Kajiyama, T. Surface molecular aggregation structure and surface molecular motions of high-molecular-weight polystyrene/low-molecular-weight poly (methyl methacrylate) blend films. Macromolecules 1998, 31, 863-869. [CrossRef]

43. Wool, R.P. Polymer Interfaces: Structure and Strength; Hanser: Cincinnati, OH, USA, 1995. 
44. Lewin, M.; Mey-Marom, A.; Frank, R. Surface free energies of polymeric materials, additives and minerals. Polym. Adv. Technol. 2005, 16, 429-441. [CrossRef]

45. Lins, L.; Bugatti, V.; Livi, S.; Gorrasi, G. Ionic liquid as surfactant agent of hydrotalcite: Influence on the final properties of polycaprolactone matrix. Polymers 2018, 10, 44. [CrossRef] [PubMed]

46. Maldarelli, C.; Jain, R.K.; Ivanov, I.B.; Ruckenstein, E. Stability of symmetric and unsymmetric thin liquid films to short and long wavelength perturbations. J. Colloid Interface Sci. 1980, 78, 118-143. [CrossRef]

47. De Silva, J.; Geoghegan, M.; Higgins, A.; Krausch, G.; David, M.-O.; Reiter, G. Switching layer stability in a polymer bilayer by thickness variation. Phys. Rev. Lett. 2007, 98, 267802. [CrossRef]

48. Lu, N.; Zhang, W.; Weng, Y.; Chen, X.; Cheng, Y.; Zhou, P. Fabrication of PDMS surfaces with micro patterns and the effect of pattern sizes on bacteria adhesion. Food Control 2016, 68, 344-351. [CrossRef]

49. Hochbaum, A.I.; Aizenberg, J. Bacteria pattern spontaneously on periodic nanostructure arrays. Nano Lett. 2010, 10, 3717-3721. [CrossRef]

(C) 2019 by the authors. Licensee MDPI, Basel, Switzerland. This article is an open access article distributed under the terms and conditions of the Creative Commons Attribution (CC BY) license (http://creativecommons.org/licenses/by/4.0/). 